\title{
CONTROVERSY
}

\section{Benefits of newborn circumcision: is Europe ignoring medical evidence?}

\author{
Edgar J Schoen
}

A major difference between the paediatric care provided in Europe and that provided in the US stems from the attitudes of care providers toward newborn circumcision as a preventive health measure. In the US, the great majority of newborn boys (about 1.4 million annually) are circumcised, whereas in Europe, neonatal circumcision is rarely done. European countries consider newborn circumcision an unnecessary surgical procedure which increases the costs of operating nationalised health systems, whereas in the US, circumcision is generally considered a simple, rapid operation with medical benefits which accrue throughout life.

\section{Local foreskin problems and hygiene}

Phimosis, balanoposthitis, and difficulty of ensuring adequate genital hygiene in uncircumcised boys have been best described in the European literature. ${ }^{1-4}$ US anticircumcision groups claim that genital hygiene can easily be maintained as the foreskin naturally separates, but, in reality, genital hygiene in uncircumcised boys has been shown to be poor, even in British and Scandinavian middle class schoolboys. ${ }^{12}$

The prevalence of true phimosis (anatomic constriction of the preputial opening, which must be distinguished from adherent foreskin) in published studies varies from $0.3 \%$ to $0.9 \%,{ }^{5}$ but true phimosis requires circumcision later in life, when the procedure is more difficult, risky, and expensive. ${ }^{6} 7$ Balanoposthitis has been estimated to occur in $4 \%$ of uncircumcised boys, and incidence peaks at age 2 to 5 years. ${ }^{3}$ Although treatment can be conservative, late circumcision is often necessary for recurrent cases, and medical management requires additional physician visits and treatment.

Pediatrics and the

Department of

Genetics, Regional

Perinatal Screening

Program, Kaiser

Permanente Medical

Care Program,

Oakland, California, USA

Correspondence and reprint requests to: Dr Edgar J Schoen, Department of Genetics, Kaiser Permanente Medical Center, $280 \mathrm{~W}$ MacArthur Blvd, Oakland, CA 94611-5693, USA. Cancer of the penis

The evidence that circumcision protects against penile cancer is overwhelming. In the US, incidence of penile cancer in circumcised men is essentially zero (about one reported case every five years), but it is 2.2 per 100000 in uncircumcised men (about 1000 cases are reported annually). On the basis of life table analysis, Kochen and McCurdy estimated that an uncircumcised man in the US has a lifetime risk of penile cancer of one in $600 .^{8}$
During the last 50 years in the US, six major series of cancer of the penis encompassing more than 1600 cases have been reported; none of these cancer patients was circumcised in infancy. ${ }^{9}$ Human papilloma virus and smegma have been implicated in the aetiology of penile cancer. ${ }^{10}$ Of the approximately 50000 cases of cancer of the penis that have occurred in the US since the 1930s (and which resulted in about 10000 deaths), only 10 were reported in circumcised men. ${ }^{9}$ Newborn circumcision virtually eliminates this devastating threat.

\section{Urinary tract infection (UTI)}

When the American Academy of Pediatrics Task Force on Circumcision report was issued, ${ }^{5}$ data from Wiswell et al suggested that uncircumcised male infants had an increased risk of clinically significant UTI. ${ }^{11}$ Since then, the evidence has become definitive, indicating a greater than 10-fold increased risk of UTI in uncircumcised boys compared with their circumcised counterparts in the first year of life. ${ }^{12-14}$ Uncircumcised preschool boys and men are also at increased risk for UTI. ${ }^{15}{ }^{16}$ UTI in infants can lead to permanent renal parenchymal damage. ${ }^{17}$ The pathophysiological basis of UTI in uncircumcised males was convincingly demonstrated by Fussell et al in electron photomicrographs showing preferential binding of uropathic fimbriated bacteria, mainly Escherichia coli, to the sticky mucosa of the foreskin, from which point they migrate up the urethra. ${ }^{18} \mathrm{~A}$ meta-analysis of the nine major studies relating UTI to circumcision showed a mean 12-fold increased risk of UTI in uncircumcised boys. ${ }^{14}$ These worldwide studies indicated that between $0.9 \%$ and $4.2 \%$ of uncircumcised infant boys have a symptomatic UTI in the first year of life. ${ }^{14}$

UTI is particularly dangerous in the first 
Sexually transmitted disease (STD)

A link between the foreskin and STD has long been proposed. ${ }^{20-24}$ In his classic, turn-of-thecentury work on circumcision, Remondino described the protective effect of circumcision against syphilis, genital herpes, and urethritis. ${ }^{20}$ STD agents that disrupt the epithelium (syphilis, chancroid, herpes, and papilloma virus) are believed to enter through miniabrasions of the foreskin, and the warm, moist environment under the foreskin permits growth of organisms causing urethritis. ${ }^{25}$ In almost all published series, these forms of STD were more common in uncircumcised men; reports of the converse are rare. Reports from Africa beginning in the late 1980 s indicated that uncircumcised, heterosexual men were from four to eight times more likely than circumcised men to contract HIV upon exposure to infected women. ${ }^{26-29}$ Multiple reports since then were summarised in 1994 by Moses et al who found that, in 22 of 30 studies, a statistically significant increase in HIV infection occurred in uncircumcised men (a mean of four times the risk of circumcised men). ${ }^{30}$ The authors felt strongly enough about these findings to recommend adult circumcision of African men to halt the raging AIDS epidemic on that continent.

Recently Caldwell and Caldwell studied the AIDS epidemic in sub-Saharan Africa where nearly $25 \%$ of the population is HIV positive as a result of heterosexual viral transmission. ${ }^{31}$ The authors concluded that lack of male circumcision was the only factor that seemed to correlate with the exceptionally high susceptibility to HIV infection.

\section{Discussion and conclusions}

The decision to discourage newborn circumcision in the UK and the resultant decrease in the number of circumcised males occurred before the accumulation of this evidence about the protective effect of circumcision against UTI and HIV infection. Particularly in the face of an expanding worldwide AIDS epidemic, these benefits are a powerful argument in favour of encouraging universal newborn circumcision. In an editorial comment on the epidemic spread of HIV-1 in Asia, Weniger and Brown pointed out that in those countries in which circumcision is practiced (Bangladesh, Indonesia, and the Philippines) rapid sexual transmission of HIV-1 is less likely. ${ }^{32}$ When properly done, newborn circumcision is a quick, simple procedure with a low complication rate. Morbidity and costs of circumcision are much lower for newborns than they are for older patients. ${ }^{67}$

Moreover, about 70 million circumcised US males currently attest to the lack of effect of circumcision on either emotional health or sexual performance, and no objective studies indicate otherwise. As a matter of fact, evidence indicates that women in Middle America have a sexual preference for circumcised men, mainly from the standpoint of aesthetics and hygiene. ${ }^{33}$

The multiple benefits of newborn circumcision are additive over a lifetime and include prevention of cancer of the penis, of balanoposthitis, and protection against the effects of phimosis and poor hygiene as well as prevention of UTI and STD, particularly of HIV. Protection against these diseases constitutes a substantial public health advantage and provides a strong argument in favour of instituting universal newborn circumcision in Europe. With AIDS spreading rapidly in developed Western countries in persons who practice heterosexual behaviour as well as in men who practice homosexual behaviour, implementation of universal circumcision beginning with Europe is prudent and timely.

The Medical Editing Department, Kaiser Foundation Research Institute, provided editorial assistance.

1 Kalcev B. Circumcision and personal hygiene in school boys. Medical Officer 1964;112:171-3.

2 Oster J. Further fate of the foreskin: incidence of preputial adhesions, phimosis, and smegma among Danish schooladhesions, phimosis, and smegma
boys. Arch Dis Child 1968;43:200-3.

3 Escala JM, Rickwood AMK. Balanitis. Br F Urol 1989;63: 196-7.

4 Winberg J, Bollgren I, Gothefors L, Herthelius M, Tullus K. The prepuce: a mistake of nature? Lancet 1989;i:598-9.

5 American Academy of Pediatrics. Report of the task force on circumcision. Pediatrics 1989;84:388-91 [published erratum appears in Pediatrics 1989;84:761].

6 Wiswell TE, Tencer HL, Welch CA, Chamberlain JL. Circumcision in children beyond the neonatal period. Pediatrics 1993;92:791-3.

7 Larsen GL, Williams SD. Postneonatal circumcision: population profile. Pediatrics 1990;85:808-12.

8 Kochen M, McCurdy S. Circumcision and the risk of cancer of the penis: a life-table analysis. Am $\mathcal{F}$ Dis Child 1980; 134:484-6.

9 Schoen EJ. The relationship between circumcision and cancer of the penis. CA Cancer F Clin 1991;41:306-9.

$10 \mathrm{McCance}$ DJ, Kalache A, Ashdown K, et al. Human papillomavirus types 16 and 18 in carcinomas of the penis from Brazil. Int $\mathcal{f}$ Cancer 1986;37:55-9.

11 Wiswell TE, Smith FR, Bass JW. Decreased incidence of urinary tract infections in circumcised male infants. Pediatrics 1985;75:901-3.

12 Wiswell TE, Miller GM, Gelston HM Jr, Jones SK, Clemmings AF. Effect of circumcision status on periurethral bacterial flora during the first year of life. $\mathcal{F}$ Pediatr 1988;113:442-6

13 Crain EF, Gershel JC. Urinary tract infections in febrile infants younger than 8 weeks of age. Pediatrics 1990;86: 363-7.

14 Wiswell TE, John K. Lattimer lecture. Prepuce presence portends prevalence of potentially perilous periurethral pathogens. F Urol 1992;148(2 pt 2):739-42.

15 Spach DH, Stapelton AE, Stamm WE. Lack of circumcision increases the risk of urinary tract infection in young men. increases the risk of urinary

16 Craig JC, Knight JF, Sureshkumar P, Mantz E, Roy LP. Effect of circumcision on incidence of urinary tract Effect of circumcision on incidence of urinary
infection in preschool boys. F Pediatr 1996;128:23-7.

17 Rushton HG, Majd M. Pyelonephritis in male infants: how important is the foreskin? f Urol 1992;148(2 pt 2):733-6; discussion 737-8.

8 Fussell EN, Kaack BM, Cherry R, Roberts JA. Adherence of bacteria to human foreskins. $\mathcal{F}$ Urol 1988;140:997-1001.

19 Wiswell TE, Geschke DW. Risks from circumcision during the first month of life compared with those for uncircumcised boys. Pediatrics 1989;83:1011-5.

20 Remondino PC. History of circumcision from the earliest times to the present: moral and physical reasons for its performance, with a history of eunuchism, hermaphrodism, etc and of the difwith a history of eunuchism, hermaphrodism, etc and of the different operations practiced upon the prepuce. Philadelphia:
Davis, 1891, 1900. (Physicians' and students' ready Davis, 1891, 1900. (Phy

21 Wilson RA. Circumcision and venereal disease. Can Med Assoc f 1947;56:54-6.

22 Parker SW, Stewart AJ, Wren MN, Gollow MM, Straton JAY. Circumcision and sexually transmissible disease. Med f Aust 1983;ii:288-90.

23 Taylor PK, Rodin P. Herpes genitalia and circumcision. British fournal of Venereal Diseases 1975;51:274-7.

24 Thirumoorthy T, Sng EH, Doraisingham S, Ling AK, Lim $\mathrm{KB}$, Lee CT. Purulent penile ulcers of patients in Singapore. Genitourin Med 1986;62:253-5.

25 Fink AJ. A possible explanation for heterosexual male infection with AIDS [letter]. $N$ Engl f Med 1986;315: 1167 .

26 Simonsen JN, Cameron DW, Gakinya MN, et al. Human immunodeficiency virus infection among men with sexually transmitted diseases: experiences from a center in Africa. $N$ Engl F Med 1988;319:274-8. 
27 Cameron DW, Simonsen JN, D'Costa LJ, et al. Female to male transmission of human immunodeficiency virus type 1: risk factors for seroconversion in men. Lancet 1989;ii: 403-7.

28 Bongaarts J, Reining P, Way P, Conant F. The relationship between male circumcision and HIV infection in African populations. AIDS 1989;3:373-7

29 Moses S, Bradley JE, Nagelkerke MJD, Ronald AR, Ndinya Achola JO, Plummer FA. Geographical patterns of male circumcision practice in Africa: association with HIV seroprevalence. Int f Epidemiol 1990;19:693-7.

30 Moses S, Plummer FA, Bradley JE, Ndinya-Achola JO, Nagelkerke NJD, Ronald AR. The association between lack of male circumcision and risk for HIV infection: a review of the epidemiological data. Sex Transm Dis 1994;21:201-10

31 Caldwell JC, Caldwell P. The African AIDS epidemic. Sci Am 1996 Mar;274(3):62-8.

32 Weniger BG, Brown T. The march of AIDS through Asia [editorial]. N Engl F Med 1996;335:343-5.

33 Williamson ML, Williamson PS. Women's preferences for penile circumcision in sexual partners. Fournal of Sex Education and Therapy 1988 Fall/Winter;14(2):9-12.

\section{Commentary}

The above paper by Schoen reflects the influence of culture and habit on the interpretation of medical practice. The practice of neonatal circumcision, so rare in Europe and ubiquitous in the USA, has been discussed. The author credits Europe with avoiding neonatal circumcision on cost grounds. I think this is a basic misconception. The practice of medicine in Europe is far less invasive than in the US and medical intervention, particularly irreversible mutilating surgery, is avoided unless there is a proved medical benefit. The morbidity of neonatal circumcision is occasionally significant, and recent evidence demonstrating evidence of altered pain responses in infants after neonatal circumcision suggests that the unperceived morbidity may be significantly higher. ${ }^{1}$

Balanitis xerotica obliterans is usually considered an absolute indication of childhood circumcision, but has an incidence significantly under $1 \%$, with a peak incidence at $6-10$ years. Balanoprosthitis occurs in up to $4 \%$ of uncircumcised boys, but fewer than $1 \%$ go on to three episodes or more of this minor local infection. Where these justify intervention we have learnt from our European colleagues of the value of preputioplasty, which saves the prepuce and has much less morbidity than circumcision. It is rare that physiological phimosis fails to resolve spontaneously and also is treatable by preputioplasty.

Circumcision as an alternative to hygiene in prevention of penile carcinoma, is an oft voiced argument. The author has quoted figures based on the 1971 national cancer survey (US) and extrapolated from the unsupported assumption that all penile carcinomas occurred in uncircumcised males. ${ }^{2}$ More recent data calculate the relative risk in the US to be 3.2 times greater in the intact male. ${ }^{3}$ Using the author's own source, the quoted incidence of penile carcinoma in the US was one per 100000 (1969-71). This is a comparable incidence with that in Finland ${ }^{4}$ at the same time, where the circumcision rate is less than $1 \%$, of 0.5 per 100000 (1970) with a $78 \%$ relative 20 year survival rate. Thus, I find Marshall's argument at a meeting of the Society for Paediatric Urology, that one would have to perform 140 circumcisions a week, for 25 years, to prevent one case of carcinoma of the penis, enough to prevent me from setting out on such a course. ${ }^{5}$

The strongest argument in favour of neonatal circumcision is the recognition that circumcision removes a reservoir of bacteria, associated with urinary tract infection, and indeed, in the child with an abnormal urinary tract where prophylaxis has failed to prevent urinary tract infection, I also practice circumcision. The author identifies, however, a paper that reports a pattern of male urinary tract infection in the first month, unassociated with renal tract anomaly, which we rarely see in the UK, and perhaps is linked to the practice of forcible preputial retraction (Rushton et $a l^{6}$; discussion). The protection of vulnerable infants with abnormal urinary tracts, possible pre-existing renal dysplasia, and a risk of new scar formation, would be better assured by renal ultrasound and family history screening.

The author's extrapolation of knowledge that circumcision reduces the transmission rate of HIV within the unprotected population of developing countries, to a belief that this has a role within the European population, is I feel, irrelevant where barrier contraceptives are readily available and considerably more efficacious.

Finally, there are now strong pressure groups (NOCIRC and INTACT), largely in North America, protesting against the perceived assault of circumcision. Duckett estimates a million adult males in the US would pay significant fees for a preputial reconstruction when its possible. ${ }^{5}$

In countries where neonatal circumcision is rarely practised, and appropriate nonaggressive management of the normal foreskin, with non-forcible retraction and regular cleaning after spontaneous relaxation of the physiological phimosis, there is no medical or popu-lation demand for neonatal circumcision. This supports the conclusion that neonatal circumcision is a social ritual with a grain of medical origin, and aligns with the recent guidelines of the Canadian Paediatric Society, that 'circumcision of newborns should not be routinely performed'.

ROWENA HITCHCOCK Department of Paediatric Surgery, John Radcliffe Hospital, Headley Way, Headington, Oxford OX3 9DU

1 Taddio A, Goldbach M, Ipp M, Stevens B, Koren G. Effect of neonatal circumcision on pain responses during vaccination in boys. Lancet (North American edition) 1995;345:291-2.

2 Kochen M, McCurdy S. Circumcision and the risk of cancer of the penis: a life-table analysis. Am $\mathcal{F}$ Dis Child 1980; 134:484-6.

3 Maden C, Sherman KJ, Beckman AM, et al. History of circumcision, medical conditions and sexual activity and risk of penile cancer. $\mathcal{F}$ Natl Cancer Inst 1993;85:19-24.

4 Maiche AG. Epidemiological aspect of cancer of the penis in Finland. Eur f Cancer Prev 1992;1:153-8.

5 Duckett JW. A temporate approach to neonatal circumci-

5 Duckett Jo. A temporate approach to neonatal circumci-
sion. Urology 1995;46:771-2.
6 Rushton HG, Majd M. Pyelonephritis in male infants: how Rushton HG, Majd M. Pyelonephritis in male infants: how
important is the foreskin? f Urol 1992;148(2 pt 2):733-6; discussion 737-8.

7 Fetus and Newborn Committee, Canadian Paediatric Society. Neonatal circumcision revisited. Can Med Assoc f 1996;154:769-80 